\title{
Academic Productivity in the Field of Otolaryngology Head and Neck Surgery from 1996 to 2019 in Regard to National Economic indicators among the countries of the Organization for Economic Co-Operation and Development
}

\author{
Lee Slutzky ${ }^{1}$, Shlomi Ritz ${ }^{1}$, Tsahi Lerman ${ }^{2}$, and Olga Reitblat ${ }^{2}$ \\ ${ }^{1}$ Hadassah University Hospital \\ ${ }^{2}$ Rabin Medical Center
}

July 16, 2020

\begin{abstract}
Abstract Background: The relation between health investment and research has been portrayed previously in several medical fields, showing a positive relation between economic resources and academic yield. Purpose: To assess the relations between various economic and bibliometric parameters in otolaryngology - head and neck surgery (ORL-HNS) of the OECD countries. Methods: Data regarding bibliometric parameters in ORL-HNS; number of publications, citations, citations per document and H index, between the years 1996 and 2019, were gathered from the Scimago Journal and Country Rank source. These data were then analysed in several breakdowns - seldom county, regional and language comparisons, in order to assess variations in ORLHNS scholar activity. Economic data regarding each OECD country; GDP per capita, total health expenditure as percent of the GDP and GERD as percent of the GDP were gathered from the OECD and World Bank websites. The correlation between economic and bibliometric indicators was analysed. Results: Among 209,949 documents analysed, a strong correlation was found between $\mathrm{H}$ index and health expenditure $(\mathrm{r}=0.734, \mathrm{p}=0.000)$, and a moderate connection was found between $\mathrm{H}$ index and both GDP per capita $(\mathrm{r}=0.459, \mathrm{p}=0.005)$ and GERD as percent of GDP $(\mathrm{r}=0.579, \mathrm{p}=0.000)$. Health expenditure showed the strongest correlations to bibliometric parameters. Nonetheless, most data showed some degree of positive correlations between economics and scholar productivity. Conclusion: This study emphasizes the positive relation between scholar productivity and economic indicators, mostly health expenditure, in the OECD countries in the field of ORL-HNS, implying the importance of health investment to ORL-HNS research.
\end{abstract}

\section{Key points}

- This study reports a data analysis of ORL-HNS research of the OECD countries in the years of 19962019 and in comparison to economic indicators, all from open resource databases

- The bibliometric data was compared among different global regions innkeeping with SJR criteria and in reference to native English-speaking countries

- The bibliometric data was also analyzed in relation to economic indicators in search of correlations between said parameters.

- Different OECD regions vary in their scholar achievements; number of publications, citations and $\mathrm{H}$ index in ORL-HNS. Differences were also seen between native and non-native English-speaking countries

- Bibliometric analysis showed positive correlations between scholar and economic indicators in various degrees, with a strong correlation between $\mathrm{H}$ index and health expenditure in the field of ORL-HNS

\section{Keywords}


Otolaryngology, bibliometrics, ORL-HNS, OECD, scientometrics, H index

\section{Introduction}

Medical research is a crucial part of improvement in healthcare, and provides advancements and alterations in both diagnostics and therapeutics. One way to assess academical research is scholarly productivity, as measured by research output. Bibliometrics is a science that integrates statistics into scholar productivity and can be useful in assessing academic yield in various levels; from an individual to global standards comparisons. This growing field of research is implemented in diverse medical fields, and with various implications such as in the use of journals' impact factors and the assessment of specific literature on medical contributes.

Various parameters have been researched and studied in the use of bibliometrics in the medical field such as citation and publication count to reflect scholar productivity. But with the inherit drawbacks of these parameters a need for a more advanced parameter has risen, hence created the $\mathrm{H}$ index as published by Hirsh in 2005. This parameter allows for the comparison of different subjects whilst alimenting specific confounders such as arbitrariness and relevance of publication. Ever since, the $\mathrm{H}$ index has established as the standard of scientometrics and is used widely to evaluate and compare an individual's academic work, as well as institutions and countries.

A number of papers have been published in the field of otolaryngology - head and neck surgery (ORLHNS) concerning data of specific researchers, country to country comparison or the contribution of a specific country to overall scholarly productivity and impact. Previous studies have demonstrated a certain correlation between academic yield to percentage of gross domestic product (GDP) spent on health in other medical fields. In this article, we would like to assess national economic parameters in the Countries of the Organisation for Economic Co-operation and Development (OECD) in a period of 24 years to ORL-HNS academics.

\section{Methods}

In order to assess these correlations, we collected data referring to scholar productivity, as expressed by the number of publications, citable documents, citations, citations per document and the $\mathrm{H}$ index for the OECD countries using The Scimago Journal and Country rank (SJR) (http://www.scimagojr.com, accessed at June 26, 2020). It is an open database which includes both journals and country indicators powered by Elsevier's B.V. Scopus database. The data collected were limited to the field of ORL-HNS between the years 1996-2019. The 2018 GDP per capita (in 2010 US dollars) was collected from the World Bank (http://www.worldbank.org, accessed at accessed at June 26, 2020). Data regarding total health spending as percent of GDP (health expenditure) in 2018 were derived from the OECD Web site (https://data.oecd.org/healthres/health-spending.htm, accessed at accessed at June 26, 2020). Data regarding gross domestic expenditure in research and development as percent of the GDP (GERD) for the year 2015 or more recent (latest available) were obtained from the United Nations Educational, Scientific, and Cultural Organization (UNESCO) (http://www.unesco.org, accessed at accessed at June 26, 2020).

In order to compare different bibliometric parameters to various global regions, each of the OECD countries was categorized into a different region according to the SJR categories; North America, Latin America, Western Europe, Eastern Europe, Asiatic region, Middle East and the Pacific Region. The different regions were evaluated for bibliometric parameters. To further analyse the data retrieved, the OCED countries were labelled in accordance to their native language; native or non-native English-speaking. The same comparisons were then applied to these two groups.

\section{Statistical Analysis}

The data retrieved were recorded on Microsoft Excel spreadsheets (Microsoft 365 Office ProPlus, Microsoft Inc.) and further analysed to assess the relations between said economic parameters to scholar productivity in each OECD country. SPSS version 21 (IBM, Chicago, Il) was used for statistical analyses. Normal distribution of variables was tested analytically by the Shapiro-Wilk test. Descriptive statistics are presented as a mean \pm standard deviation (SD) for normal distributed variables and as a median with interquartile range 
(IQR) for non-normal distributed variables. The correlation between economic and bibliometric indicators was assessed by Pearson's correlation or Spearman's rank correlation, as appropriate according to the normality test. The analyses of the differences in academic productivity between native and non-native English countries and between global regions were performed using the Mann-Whitney test.

\section{Results}

A total number of 209,949 documents published between the years of 1996-2019 were analysed for this study. In that period of time, the median number of documents per country was 1967.5 with an interquartile range (IQR) of 6248.3. per OECD country, the median number of citable documents was 1875 (IQR of 5957.8), the median number of citations per document was 14.43 with an IQR of 8.42 and the median $\mathrm{H}$ index during the study period was 67.5 with and IQR of 59.3. All bibliometric data referring to each of the OECD countries are presented in Table 1 .

When equating academic parameters between the various regions, there was a statically significant difference between Eastern Europe and North American regions in the number of documents published, citable documents, citations and H index in favour to North America $(\mathrm{p}=0.044$ for all data). Similar results were seen when comparing Eastern Europe to the Asiatic Region ( $\mathrm{p}=0.044$ for all data). A statically significant higher number of documents published, citable documents, citations, citations per document and $\mathrm{H}$ index was shown in Western Europe in comparison to Eastern Europe $(p=0.005, p=0.005, p=0.001, p=0.016$ and $\mathrm{p}=0.001$, respectively). When comparing publication data between Eastern Europe to the Middle East, a significant difference in the number citations and $\mathrm{H}$ index in favour of the Middle East region was found $(\mathrm{p}=0.044)$. When comparing Western Europe to the Asiatic Region there was a difference in citations per document in favour on Western Europe $(\mathrm{p}=0.021)$ Table 2 .

When further dividing the OECD countries into native English speakers versus non-native speakers, there was a statistically significant difference in the number of citations $(\mathrm{p}=0.046)$ and $\mathrm{H}$ index $(\mathrm{p}=0.026)$, with an advantage to native English-speaking countries Table 2 .

The various economic indicators for the OECD counties are represented inTable 3 . Correlations found between economic indicators and scholarly productivity parameters are presented in Table 4 . A strong correlation was found between health expenditure and H index $(r=0.734, \mathrm{p}=0.000)$, a statistically significant moderate correlation was found between health expenditure and number of documents $(r=0.572, \mathrm{p}=0.000)$, number of citable documents $(r=0.574 \mathrm{p}=0.000)$ and number of citations $(r=0.639 \mathrm{p}=0.000)$. A statistically significant moderate correlation was also fund between the GERD as a percent GDP and the number of documents $(r=0.471 \mathrm{p}=0.004)$, number of citable documents $(r=0.471 \mathrm{p}=0.004)$, number of citations $(r=0.503 \mathrm{p}=0.002)$, number of citations per documents $(r=0.518 \mathrm{p}=0.001)$ and the $\mathrm{H}$ index $(r=0.579$ $\mathrm{p}=0.000)$. A moderate association was found between GDP per capita and the $\mathrm{H}$ index $(r=0.459 \mathrm{p}=0.005)$ and a weak correlation was found between the GDP per capita and the number of citations $(r=0.355$ $\mathrm{p}=0.034$ ). No other statistically significant correlations between economic and bibliometric indices were found.

\section{Discussion}

Bibliometric science is ever growing and establishing itself as an accurate way of estimating and portraying both scholar productivity for itself, assessing different variables connected to academic productivity or showing non-partial and affective way of critiquing one's scientific output's quality and quantity.

As ORL-HNS is a field of medicine that interphases with numerous other medical disciplines, advancements in ORL-HNS may have an effect in Oncology, Neurology, Endocrinology, Maxillofacial surgery and even Paediatrics. Therefore, many patients and medical teams can profit from research in this medical field. With a constant need in new research and development in the field of ORL-HNS, the data portrayed in this study shed an important light on the connection of economic investment in research and research output.

In this current study, we have examined the association between economic and bibliometric indicators in ORL-NHS scholar productivity of the different OECD countries and examined the association between said 
indicators. As far as we know, this is the most updated and broad study in ORL-HNS scientometrics to date.

As we've compared the various OCED countries regions there seemed to by a constant different between several bibliometric indices in Eastern Europe and almost all other region for the exception of Latin America. Moreover, a consistent difference was evident in $\mathrm{H}$ index, which is, as stated above considered to be the gold standard of scientometrics. This tendency is further fortified by the significant difference seen in native English versus non-native English-speaking countries, with an overall difference in both $\mathrm{H}$ index and number of citations. this leaning was shown in the past, though not as significantly in other medical fields by our group. These said differences may be attributed to both economic investments and to the fact that the leading language in global academics is in fact English, which may cause a publication barrier for non-native academics.

When valuating said bibliometric data against economic parameters, a strong correlation is seen between health expenditure as calculated for 2018 as percentage of the GDP and $\mathrm{H}$ index, a moderate correlation is seen between health expenditure and all other bibliometric data as well as between the GERD and all bibliometric parameters. Furthermore, we can state that the $\mathrm{H}$ index, our gold standard for scientometrics data as mentions previously, is moderately to strongly connected to any of the economic indicators examined in our study. When referring to GDP per capita, the indicator which is, out of our economic parameters, least directly linked to medical investment is where whiteness the weakest correlations with only two parameters with a significant link; citations (weak correlation) and H index (a moderate correlation).

There are several drawbacks to our study, one being the fact that the number of publications is not adjusted to the population size or number of ORL-NHS surgeons per country, data that may have significance when assessing absolute bibliometric parameters such as the number of publications or total citations. Furthermore, when evaluating large countries such as the United States there is no state-to-state breakdown, and the variations between states may be of scientific importance. Nonetheless, our comparison does allow to review the United States contribution as a whole, and its' impact on global research, and allows to assess each country's contribution regardless to its' size. Another limitation is the use of solemnly open sources, which are not always updated at the time of data collection (GDP per capita, 2018; health expenditure, 2018; GERD, latest updated). However, we believe that the still provide a satisfactorily accurate reflection of each of the OECD countries economic averages and are sufficient to prove the conclusions conducted in this article. Another drawback of the study is that it differs only to the OECD countries, and the conclusions made in it may not be generalised to the rest of the worlds' countries. In spite of this, using only OECD countries provided us with a precise data collection and made its results more valid.

As bibliometrics is crucial to accurately demonstrating scholar productivity, the results of our study enhance the importance of health expenditure and investment in science as a catalysator for academic advancement in the field of ORL-HNS, more so than general economic variables as is the GDP per capita. This assumption, mainly of health expenditure, was proven in the past in different medical fields such as Cardiology and Rheumatology. We assume that in wealthy healthcare systems, affluent with manpower and advanced infrastructure, there is more time and means for conducting research. In addition, one can argue that as clinical research is integrated with the daily medical practice, investment in health indirectly results in investment in health academics.

\section{Conclusions}

This article shows a direct connection between economic health indicators and scientific output. Notwithstanding its limitations, our study illustrates the general assumption that investment in health and health scholarship are entwined in the field of ORL-HNS and may suggest an additional need for investment in medical care. Further research in other medical fields is desired to extrapolate our conclusions to more specialties.

\section{References}

Table 1. 


\begin{tabular}{|c|c|c|c|c|c|c|}
\hline Country & Region & Documents & Citable documents & Citations & Citations per document & $\mathrm{H}$ index \\
\hline Mexico & Latin America & 699 & 672 & 8278 & 11.84 & 41 \\
\hline Turkey & Middle East & 9089 & 8565 & 82673 & 9.1 & 68 \\
\hline Chile & Latin America & 577 & 556 & 4507 & 7.81 & 29 \\
\hline Latvia & Eastern Europe & 22 & 20 & 342 & 15.55 & 10 \\
\hline Hungary & Eastern Europe & 488 & 460 & 6371 & 13.06 & 35 \\
\hline Poland & Eastern Europe & 2907 & 2799 & 17041 & 5.86 & 46 \\
\hline Lithuania & Eastern Europe & 91 & 91 & 1148 & 12.62 & 19 \\
\hline Estonia & Eastern Europe & 29 & 29 & 283 & 9.76 & 9 \\
\hline Slovakia & Eastern Europe & 225 & 221 & 1669 & 7.42 & 20 \\
\hline Czech Republic & Eastern Europe & 1177 & 1123 & 6011 & 5.11 & 34 \\
\hline Greece & Western Europe & 1874 & 1771 & 27255 & 14.54 & 63 \\
\hline Portugal & Western Europe & 692 & 658 & 7451 & 10.77 & 34 \\
\hline Slovenia & Eastern Europe & 252 & 239 & 4639 & 18.41 & 36 \\
\hline South Korea & Asiatic Region & 7204 & 6874 & 68919 & 9.57 & 67 \\
\hline Spain & Western Europe & 8037 & 7750 & 74192 & 9.23 & 76 \\
\hline Israel & Middle East & 2507 & 2417 & 43261 & 17.26 & 76 \\
\hline Italy & Western Europe & 10161 & 9512 & 129229 & 12.72 & 95 \\
\hline New Zealand & Pacific Region & 943 & 885 & 14923 & 15.83 & 54 \\
\hline United Kingdom & Western Europe & 18636 & 15912 & 264515 & 14.19 & 138 \\
\hline France & Western Europe & 7494 & 6979 & 75085 & 10.02 & 89 \\
\hline Belgium & Western Europe & 3113 & 2963 & 52834 & 16.97 & 85 \\
\hline Germany & Western Europe & 16374 & 15397 & 203841 & 12.45 & 121 \\
\hline Finland & Western Europe & 2056 & 1977 & 37999 & 18.48 & 73 \\
\hline Japan & Asiatic Region & 22999 & 22668 & 179649 & 7.81 & 101 \\
\hline Austria & Western Europe & 1879 & 1771 & 35756 & 19.03 & 76 \\
\hline Iceland & Western Europe & 39 & 36 & 728 & 18.67 & 16 \\
\hline Canada & North America & 5804 & 5535 & 103323 & 17.8 & 105 \\
\hline United States & North America & 64577 & 60212 & 1154785 & 17.88 & 216 \\
\hline Netherlands & Western Europe & 5475 & 5106 & 100554 & 18.37 & 106 \\
\hline Australia & Pacific Region & 5315 & 5010 & 94885 & 17.85 & 109 \\
\hline Sweden & Western Europe & 3203 & 3099 & 68618 & 21.42 & 96 \\
\hline Denmark & Western Europe & 1549 & 1509 & 31005 & 20.02 & 68 \\
\hline Ireland & Western Europe & 796 & 724 & 11410 & 14.33 & 45 \\
\hline Switzerland & Western Europe & 2728 & 2604 & 48352 & 17.72 & 82 \\
\hline Norway & Western Europe & 898 & 857 & 18216 & 20.29 & 61 \\
\hline Luxembourg & Western Europe & 40 & 35 & 970 & 24.25 & 10 \\
\hline
\end{tabular}

Bibliometric Data Regarding OECD Countries 1996-2019.

Table 2 .

\begin{tabular}{llllll}
\hline & Documents* & $\begin{array}{l}\text { Citable } \\
\text { documents }\end{array}$ & Citations $^{\$}$ & $\begin{array}{l}\text { Citations }_{\text {per }} \\
\text { document }^{\&}\end{array}$ & H index $^{£}$ \\
$\begin{array}{l}\text { Region } \\
\begin{array}{l}\text { North America } \\
\text { (N=2) }\end{array}\end{array}$ & 35190 & 32873.5 & 629054 & 17.84 & 160.5 \\
$\begin{array}{l}\text { Latin America } \\
(\mathrm{N}=2)\end{array}$ & 638 & 614 & 6392.5 & 9.825 & 35
\end{tabular}




\begin{tabular}{|c|c|c|c|c|c|}
\hline $\begin{array}{l}\text { Western Europe } \\
(\mathrm{N}=18)\end{array}$ & 2392 & 2290.5 & 43175.5 & 17.345 & 76 \\
\hline $\begin{array}{l}\text { Eastern Europe } \\
(\mathrm{N}=8)\end{array}$ & 238.5 & 230 & 3154 & 11.19 & 27 \\
\hline $\begin{array}{l}\text { Asiatic region } \\
(\mathrm{N}=2)\end{array}$ & 15101.5 & 14771 & 124284 & 8.69 & 84 \\
\hline $\begin{array}{l}\text { Middle East } \\
(\mathrm{N}=2)\end{array}$ & 5798 & 5491 & 62967 & 13.18 & 72 \\
\hline $\begin{array}{l}\text { Pacific Region } \\
(\mathrm{N}=2)\end{array}$ & 3129 & 2947 & 54904 & 16.84 & 81.5 \\
\hline English & & & & & \\
\hline Speaking & & & & & \\
\hline $\begin{array}{l}\text { Non-native } \\
(\mathrm{N}=30)\end{array}$ & 1876.5 & 1771 & 29130 & 13.625 & 65 \\
\hline Native $(\mathrm{n}=6)$ & 1967.5 & 1874 & 3380.5 & 14.435 & 67.5 \\
\hline
\end{tabular}

Median values are presented

Bibliometric Data Regarding OECD Countries 1996-2019 by Regions and Language.

* Eastern Europe < North America, Western Europe, Asiatic region $(\mathrm{p}<0.05)$

Region $(\mathrm{p}<0.05)$

$\$$ Eastern Europe $<$ North America, Western Europe, Asiatic Region, Middle East $(\mathrm{p}<0.05)$, Non-native $<$ Native $(\mathrm{p}<0.05)$

\& Eastern Europe $<$ Western Europe $(\mathrm{p}<0.05)$, Asiatic Region $<$ Western Europe $(\mathrm{p}<0.05)$

$£$ Eastern Europe $<$ North America, Western Europe, Asiatic Region, Middle East, Pacific Region $(\mathrm{P}<0.05)$, Non-native $<$ Native $(\mathrm{p}<0.05)$

Table 3 .

\begin{tabular}{llll}
\hline Country & GDP per capita (constant 2010 US\$) & Health Expenditure 2018 (\%GDP) & GERD as percent of GDP \\
\hline Mexico & $10,403.50$ & 5.457 & 0.313 \\
Turkey & $15,069.00$ & 4.172 & 0.96 \\
Chile & $15,130.20$ & 8.911 & 0.355 \\
Latvia & $16,269.00$ & 5.866 & 0.639 \\
Hungary & $16,647.70$ & 6.593 & 1.533 \\
Poland & $16,659.30$ & 6.288 & 1.213 \\
Lithuania & $17,708.50$ & 6.805 & 0.877 \\
Estonia & $19,954.10$ & 6.449 & 1.404 \\
Slovakia & $20,599.10$ & 6.729 & 0.837 \\
Czech Republic & $23,358.90$ & 7.515 & 1.93 \\
Greece & $23,558.10$ & 7.846 & 1.177 \\
Portugal & $23,994.70$ & 9.099 & 1.35 \\
Slovenia & $26,768.40$ & 7.946 & 1.95 \\
South Korea & $26,761.90$ & 8.102 & 4.528 \\
Spain & $32,949.60$ & 8.86 & 1.243 \\
Israel & $34,745.80$ & 7.463 & 4.941 \\
Italy & $35,431.90$ & 8.813 & 1.392 \\
New Zealand & $37,997.40$ & 9.341 & 1.366 \\
United Kingdom & $43,324.60$ & 9.768 & 1.706
\end{tabular}




\begin{tabular}{llll}
\hline Country & GDP per capita (constant 2010 US\$) & Health Expenditure 2018 (\%GDP) & GERD as percent of GDP \\
\hline France & $43,663.60$ & 11.177 & 2.2 \\
Belgium & $47,166.50$ & 10.372 & 2.764 \\
Germany & $47,477.80$ & 11.229 & 3.133 \\
Finland & $48,749.10$ & 9.075 & 2.746 \\
Japan & $48,919.80$ & 10.918 & 3.264 \\
Austria & $50,019.90$ & 10.33 & 3.217 \\
Iceland & $52,103.20$ & 8.34 & 2.03 \\
Canada & $51,391.70$ & 10.734 & 1.541 \\
United States & $54,579.00$ & 16.937 & 2.826 \\
Netherlands & $55,022.90$ & 9.941 & 2.164 \\
Australia & $56,842.30$ & 9.252 & 1.789 \\
Sweden & $57,921.40$ & 11.037 & 3.309 \\
Denmark & $63,873.50$ & 10.47 & 3.033 \\
Ireland & $76,880.80$ & 7.095 & 1.146 \\
Switzerland & $79,214.40$ & 12.183 & 3.368 \\
Norway & $92,077.60$ & 10.182 & 2.073 \\
Luxembourg & $110,742.30$ & 5.408 & 1.211 \\
\hline
\end{tabular}

Economic Indicators for the OECD Countries in 1996-2019: GDP per Capita, Total Health Expenditure as \%GDP, Gross Domestic Expenditure on Research and Development (GERD) as \%GDP.

Table 4.

\begin{tabular}{llllll}
\hline & & Documents & Citable documents & Citations & Citations p \\
\hline GDP per capita (constant 2010 US\$) & Correlation Coefficient & .249 & .245 & .355 & .309 \\
& p-value & .143 & .150 & .034 & .067 \\
Health Expenditure 2018 (\%GDP) & Correlation Coefficient & .572 & .574 & .639 & $.304^{*}$ \\
& p-value & .000 & .000 & .000 & .072 \\
GERD as percent of GDP & Correlation Coefficient & .471 & .471 & .503 & .518 \\
& p-value & .004 & .004 & .002 & .001 \\
\hline
\end{tabular}

Correlation Analysis Between Economic and Bibliometric Indicators.

All data analysed as Spearman's correlation unless pointed otherwise.

*Pearson Correlation 